\title{
OS PADRÕES DOS LIVROS DE LIÇÕES DE COISAS
}

\author{
Los patrones de libros de texto de lecciones de cosas
}

The patterns of textbooks of objecte lessons

Kazumi Munakata ${ }^{1}$

\begin{abstract}
Resumo
As lições de coisas, em geral conhecidas também como "método intuitivo", constituem proposta pedagógica que preconiza o contato direto do educando com o mundo, pela observação, experimentação e manipulação, em vez de conhecê-lo pela leitura dos livros. Apesar disso, produziram-se na França, Itália, Espanha e Brasil (e possivelmente também em outros lugares), muitos livros didáticos de lições de coisas. Quais são, então, os padrões de linguagem desses livros? Este artigo faz parte do projeto de pesquisa "Das palavras às coisas: mudanças nos padrões de ensino no Ocidente, no século XIX e início do XX", financiada pelo Conselho Nacional de Desenvolvimento Científico e Tecnológico (CNPq), entre 2013-2016. A pesquisa adota a perspectiva transnacional, que aborda a circulação em dimensões globais, internacionais, transnacionais, regionais e locais de ideias, significados e práticas e suas apropriações. Por isso mesmo a pesquisa baseou-se em arquivos do Brasil, Espanha e Argentina, além de acervos virtuais. A conclusão básica é a de que os livros didáticos de lições de coisas dividem-se em dois padrões de linguagem, a saber, os com narrativa e os sem narrativa; este último padrão possibilita a construção de uma moral utilitarista.
\end{abstract}

PALAVRAS-CHAVE: Lições de coisas. Livro didático. Utilitarismo.

\begin{abstract}
The object lessons, also known as "intuitive method", are pedagogical proposals that advocate the direct contact of the student with the world, through observation, experimentation and manipulation, instead of knowing it through the reading books. Despite this, many textbooks of object lessons have been produced in France, Italy, Spain and Brazil (and possibly elsewhere). Then, which are the language patterns of these books? This article is part of the research project "From words to things: changes in teaching patterns in the West, in the nineteenth century and the beginning of the twentieth century", financed by the Conselho Nacional de Desenvolvimento Científico e Tecnológico (CNPq) between 2013-2016. The research adopts the transnational perspective, which examines the circulation of ideas, meanings and practices and their appropriations in global, international, transnational, regional and local dimensions. For this reason the research was based on archives of Brazil, Spain and Argentina, as well as virtual collections. The basic conclusion is that the textbooks of the object lessons are divided into two patterns of language, namely, narrative and non-narrative; this latter pattern enables the construction of a utilitarian moral.
\end{abstract}

KEYWORDS: Object lessons. Textbook. Utilitarianism.

\footnotetext{
${ }^{1}$ Doutor em História e Filosofia da Educação pela PUC-SP. Professor da Pontifícia Universidade Católica de São Paulo. E-mail: kazumi.munakata@gmail.com
} 


\section{Resumén}

Las lecciones de cosas, en general conocidas también como "método intuitivo", constituyen una propuesta pedagógica que preconiza el contacto directo del educando con el mundo, por la observación, experimentación y manipulación, en vez de conocerlo por la lectura de los libros. A pesar de ello, se produjeron en Francia, Italia, España y Brasil (y posiblemente también en otros lugares), muchos libros didácticos de lecciones de cosas. ¿Cuáles son entonces los patrones de lenguaje de estos libros? Este artículo forma parte del proyecto de investigación "De las palabras a las cosas: cambios en los patrones de enseñanza en Occidente, en el siglo XIX e inicio del XX", financiada por el Conselho Nacional de Desenvolvimento Científico e Tecnológico (CNPq), entre 2013-2016. La investigación adopta la perspectiva transnacional, que aborda la circulación en dimensiones globales, internacionales, transnacionales, regionales y locales de ideas, significados y prácticas y sus apropiaciones. Por eso mismo la investigación se basó en archivos de Brasil, España y Argentina, además de acervos virtuales. La conclusión básica es que los libros didácticos de lecciones de cosas se dividen en dos patrones de lenguaje, a saber, los con narrativa y los sin narrativa; este último estándar posibilita la construcción de una moral utilitarista.

PALABRAS CLAVE: Lecciones de cosas. Libro de texto. Utilitarismo.

\section{INTRODUÇÃO}

A rigor, as lições de coisas não deveriam admitir livros didáticos. Formulada contra a chamada "cultura livresca", essa proposta pedagógica exigia observar as coisas, fazer a experiência do mundo pelos cinco sentidos, pela intuição. ${ }^{1}$ De fato, nos Estados Unidos, as lições de coisas deviam-se basear nas aulas orais, como sempre enfatiza Schelbauer (2003, p. $43,46,69,113)$. Por levar ao pé da letra a recusa ao ensino "livresco", não há livros didáticos na produção norte-americana sobre lições de coisas. O que há são obras como as de Calkins (1886), Sheldon (1872) Lake (1858) ou George Ricks (1895), que são sempre manuais para professores.

Esse princípio da interdição dos livros e da cultura livresca não impediu, no entanto, que se produzissem na França e na Espanha (e também na Itália e no Brasil) obras não apenas de caráter teórico e metodológico para professores e estudiosos, mas também livros didáticos em profusão, que até chegaram a se distribuir entre as séries de ensino, formando coleções. Afinal, como declara Kahn (2002, p. 172), “(...) ninguém, aparentemente, se espanta diante da contradição em termos que encerra a idéia de um livro de lição de coisas. O mercado editorial, sem dúvida, sai ganhando mais do que a coerência da teoria".

Além disso, como também alerta Kahn (2002, pp. 222-223), “'Lições de coisas’ é um lexema complexo, e os contextos de enunciações são determinantes para compreender, em cada caso, qual é o sentido preponderante". Por isso, em vez de buscar uma unidade teórica e metodológica das lições de coisas e/ou do método intuitivo, ele propõe rastrear a história de suas

origens diversas, que não é tão fácil de articular: origens filosóficas, geográficas, institucionais... Entre Comenius, a América e a escola maternal [salles d'asile], por

\footnotetext{
${ }^{1}$ Hoje há relativamente vasta bibliografia sobre o método intuitivo e/ou lições de coisas e, por isso, aqui se dispensa elucidação pormenorizada sobre o tema. Consultem-se, entre outros, Souza (1999), Bianco (1999), Schelbauer (2003), Valdemarin (2004), Medina (2012).
} 
exemplo, a lição de coisas aparece como um resultado sincrético da reflexão pedagógica. [...] Esse sincretismo se observa também na terminologia, que nunca foi [...] fixada. Daí a polissemia, que parece irredutível, da lição de coisas (KAHN, 2002, p. 168).

Daí, o que Kahn (2002, p. 150 ss.) denomina "geo-pedagogia", ou seja, a distribuição geográfica das inspirações de que se apropriaram na França: a Alemanha e os Estados Unidos.

Nos países de língua alemã, segundo Melcón Beltrán (2000, pp. 136-137), a tradição reformadora de Comenius (1692-1670), Francke (1663-1727) e Pestalozzi enfatizou o estudo de coisas comuns e úteis (Realien, ou "ensinos reais"). Em 1895, o programa da instrução primária de Genebra (Suíça) contava com "Lições de Coisas e História Natural (MELCÓN BELTRÁN, 2000, p. 139). Kahn (2002) também comenta que o padrão alemão das lições de coisas está presente no ensino primário, mas também nas "Realschulen (Escolas reais), que acolhem crianças de 10 a 15 anos e cuja finalidade é (...) de substituir o ensino exclusivo das palavras pelo das realidades" (MELCÓN BELTRÁN, 2000, p. 151-152). Sobre os livros didáticos utilizados, a bibliografia consultada não faz nenhuma menção. ${ }^{2}$

Em relação aos Estados Unidos, os franceses, de acordo com Kahn (2002, p. 153), mantêm um "olhar admirador e tocquevilleano: ela [a "França pedagogizante"] vê no projeto e nos métodos da escola americana o futuro da democracia". O termo "lições de coisas" ("lessons de choses") é uma adaptação do inglês "object lessons"; além disso,

a maneira pela qual os americanos concebem a lição de coisas é clara: trata-se de um ensino positivo sobre os fenômenos da natureza, que os alunos devem aprender primeiro a observar. De saída, a América situa as lições de coisas ao lado do ensino de ciências [...]. (KAHN, 2002, p. 154).

Onde as lições de coisas converteram-se em livros, podem se identificar duas modalidades discursivas: as com narrativa e as sem narrativa. ${ }^{3}$ As obras de Mme. PapeCarpentier (1815-1878) constituem, talvez, o caso mais óbvio de livros de lições de coisas com narrativa. Histoires et Leçons de Choses (1904), uma de suas obras, é um alentado livro de mais de 300 páginas, com historietas para crianças, como "A menina pequena e o gato pequeno", "A galinha e seus pintinhos", "O buquê de violetas" etc. Por exemplo, o capítulo V, "Uma ninhada de amigos" (Une nichée d'amis): um cão de guarda, que ficava sempre preso a uma corrente e vivia entediado, cede o seu abrigo para Minette, uma gata, para que ela pudesse ter filhotes; estes passam a brincar com o cachorro, que não mais fica entediado e

\footnotetext{
${ }^{2}$ Caruso (2005, p. 224 ss.) afirma que na "última metade do século XVIII, Baviera fora pioneira na organização centralizada de uma política de texto escolar que incluía, em especial, a existência de um monopólio de impressão de textos escolares [...]. Ainda que o monopólio editorial fosse abolido em 1849, a política de aprovação dos textos escolares permaneceu centralizada em mãos estatais [...]” (p. 225). O autor, no entanto, não menciona o conteúdo desses "textos escolares", mas, noutra passagem, faz menção a "lâminas para lições de coisas” (p. 228). Uma rápida busca na Internet revela capas de livros de Anschauungsunterricht, que literalmente significa "ensino visual" ou "ensino pela intuição". Em todo caso, essa questão merece mais elucidação.

3 Segundo o verbete "Narração", de Jean-Michel Adam, no Dicionário de Análise do Discurso (CHARAUDEAU; MAINGUENEAU, 2004, p. 342), "para que haja narrativa, inicialmente é preciso a representação de uma sucessão temporal de ações; em seguida, que uma transformação mais ou menos importante de certas propriedades iniciais dos actantes seja bem sucedida ou fracassada, enfim, é preciso que uma elaboração da intriga estruture e dê sentido a essa sucessão de ações e de eventos no tempo".
} 
infeliz. (PAPE-CARPENTIER, 1911, p. 22-23) A narrativa permanece mesmo num livro intitulado Ensino pelos Olhos: Zoologia para Escola Maternal e Famílias (Enseignement par les yeux. Zoologie des salles d'asile et des familles), de 1911 (9a. ed.): embora o título enfatize a importância do olhar - e, portanto, da observação - há poucos recursos visuais (desenhos) e os conteúdos, as explicações sobre cada animal, aparecem sob a forma da narrativa. $\mathrm{O}$ capítulo sobre o tigre, por exemplo:

- Ah! Que gato grande! Venham ver! Georges, Abel, venham ver!

- Ah! ah! Marie chama este animal de gato! Ela é doida! Esse é um tigre...

- De Bengala, ainda por cima! acrescentou Abel.

- Você é bem sabido, hein? respondeu Georges. Onde viu que é de Bengala?

- Vamos, vamos, minhas crianças, não zombem de sua irmã... Não está tão errado o que ela disse. Um cientista, sem desmentir vocês, dar-lhe-ia razão: um tigre é, de fato, um gato grande. (PAPE-CARPENTIER, 1911, p. 65.)

Assim, a mãe de Marie, Georges e Abel inicia a sua explicação sobre o tigre, contando-lhes sobre o gênero a que o animal pertence, a descrição de seu corpo, da pelagem, seu habitat e modo de vida, sua alimentação, animais selvagens do mesmo gênero etc. A narrativa se encerra afastando-se do campo estrito da Zoologia: a menina pergunta o motivo pelo qual esses animais ferozes ocorrem apenas em certas regiões (por exemplo, na Índia) e não no seu país, no caso a França, e a mãe lhe responde que "os animais ferozes desapareceram diante do progresso da civilização". A filha, então, conclama: "Então, meus irmãos (...), instruamo-nos e civilizemo-nos, a fim de fazer desaparecer de nosso país os animais ferozes de toda espécie" (PAPE-CARPENTIER, 1911, p. 75).

Esse modelo, de certo modo, está presente na famosa obra de G. Bruno (pseudônimo de Augustine Fouillée), Le tour de France par deux enfants, cuja primeira edição é de 1877. O seu subtítulo é "Livre de lecture courante avec 200 gravures instructives pour leçons de choses (Livro de leitura corrente com 200 gravuras instrutivas para lições de coisas)" e, como descreve Hébrard (2002, p. 63), cada

capítulo desse livro [...] era uma verdadeira "lição" (de história, de geografia, de ciências, é claro, mas sobretudo lição de moral), trazida pelas peripécias de uma viagem através da França. André e Julien descobriam os monumentos, as paisagens, as técnicas de trabalho e construíam, no decorrer do tempo, uma nova representação do mundo: variedades do seu país, dureza dos tempos, solidariedade dos homens."

Como se sabe, esse livro inspiraria Através do Brasil, de Olavo Bilac e Manoel Bonfim, publicado em 1910. Do mesmo modo, no México, segundo Martínez Moctezuma (2010, p. 205), publicou-se, em 1907, Viaje a través de México por dos niños huérfanos, de Lucio Tapia. Ainda segundo Martínez Moctezuma (2010, p. 207), tratava-se do "conhecimento da Pátria mexicana" e, para tal, "seguindo o procedimento intuitivo que sugeria a pedagogia da época, havia que ver, observar e aproximar-se de tudo o que rodeava as crianças (...)". Nesses livros - e certamente há outros congêneres pelo mundo -, a narrativa serve de fio condutor para a exposição dos mais diversos conteúdos, cujo critério de enumeração não é disciplinar, mas a trama em que se envolvem os personagens. Mais tarde, nos anos 1930, a experiência de mesclar a disciplina escolar com a narrativa foi empreendida pelo escritor brasileiro Monteiro Lobato, que procurou expor, em meio às peripécias dos personagens de sua obra infantil, a História Geral, a Geografia, a Gramática ou a Aritmética (ALCANFOR, 2010). As disciplinas escolares, no entanto, já haviam consolidado a sua retórica, que não comportava mais a narrativa. 
Os elementos ficcionais também estão presentes mesmo em livros que pretendem apresentar explicações sobre alguma coisa específica, seguindo o princípio geral de lição de coisas: minerais, vegetais, animais, fenômenos naturais, artefatos produzidos pelo homem, o corpo humano, os órgãos dos sentidos etc. Por exemplo, a lição sobre a extração do sal pela evaporação da água salinizado, em Lições de Cousas. Leituras praticas (s.d.), de C. Jost e V. Humbert (p. 75): ${ }^{4}$

Pedro ficou muito admirado com o que seu avô lhe contára a respeito do sal.

Adivinhai o que elle fez:

Derreteu uns punhados de sal n'um jarro d'agua.

Depois do sal estar derretido, e da agua estar bem salgada, disse comsigo: "Agora vou vêr se, fazendo seccar a agua salgada, tambem eu obtenho sal."

Vasou alguma agua n'uma travessa grande; e expôz a travessa ao sol.

[...] Qual não foi a alegria do nosso amiguinho quando viu alguns grãos de sal muito finos no fundo da travessa! (s.d.) $:^{5}$

Ou, então, a lição sobre "A terra e os astros”, em Lições de Cousas, de Dr. Saffray

Supõe que caminhas por uma planície em direcção a uma aldeia situada a meia légua de distancia. Logo que seja possível distinguir os objectos do horisonte, como se costuma dizer, a primeira cousa que vês é o vertice do campanario, e não a egreja, nem as arvores nem as casas; alguma coisa as esconde. Esta planície não é uma superficie plana como uma mesa, mas sim uma porção de uma esphera; fórma portanto uma curvatura, que produz o effeito de uma collina collocada entre ti e o campanario. (p. 7-8, grifos do autor.)

No livro Lezione di Cose: secondo l'ordine naturale intuitivo (1880), italiano, de Virginia Staurenghi Consiglio (1848-1921), a lição sobre a sensibilidade começa com uma conversa entre a professora e os alunos - como também acontece nas demais lições da obra:

- Oh, que belas flores!

- Oh, lindas flores!

- Você gosta disso, não é? Na verdade, as flores são uma ótima coisa! (A professora se aproxima dos alunos). Observe-as, veja como são lindas!

- Elas são lindas! e como eles o cheiram! Esse jasmim especialmente. (STAURENGHI CONSIGLIO, 1880, p. 23.)

Para além da explicação sobre uma coisa, a narrativa promove ocasiões para extrapolar o conteúdo propriamente dito da lição, para introduzir comentários, como se viu acima a respeito de tigres. De modo geral, esses comentários apresentam juízos de valor,

\footnotetext{
${ }^{4}$ No Brasil, um dos autores deste livro foi equivocadamente grafado como C. Jost. Trata-se, na realidade, de Guillaume Jost (1831-1907) (Cf. http://catalogue.bnf.fr/ark:/12148/cb306613101, Acesso em: 1 jul. 2017). Não foram encontradas informações sobre V. Humbert. A edição brasileira do livro, aqui utilizada, é de H. Garnier Editor, do Rio de Janeiro, mas foi impresso em Paris, França, e contém um prefácio da 12a. edição.

${ }^{5}$ O nome do autor, que assinava Dr. Saffray, é Charles Saffray (1833-1890), médico, botânico e professor de fisiologia (cf. http://data.bnf.fr/15287949/charles_saffray/. aAcesso em: 1 jul. 2017). A edição francesa disponível é a sexta (1888), que contém o prefácio de 1880. A edição brasileira, aqui utilizada, contém a informação de que o livro foi traduzido da "ultima edição francesa" e que recebeu "Grande prémio na Exposição do Rio de Janeiro de 1908".
} 
morais ou estéticos - que, por sinal, também constituem os objetivos educacionais das lições de coisas. A religião também se insinua, subreptícia, como em Otras Lecciones de Cosas (Lecturas científicas), de Joaquín Pla Cargol (1935), em lição denominada "Não há nada depreciável": 6

\begin{abstract}
Os objetos mais insignificantes e vulgares têm também sua importância; somente a nossa ignorância nos faz depreciar, algumas vezes, por inúteis, coisas que, em verdade, distam em muito de merecer tal abandono.

[...] Deus é infinito, e não criou nada que fosse desnecessário de todo: devemos, pois, procurar ver o aspecto útil de cada coisa (PLA CARGOL, 1935, p. 5 e 7.)
\end{abstract}

Páginas adiante, na lição sobre "A linguagem", lê-se: "O dom maior que Deus concedeu ao homem é, sem dúvida, o dom da palavra”. (PLA CARGOL, 1935, p. 9).

As lições sem narrativa dificultam esses comentários de caráter moral e cristão. Obra característica dessa vertente é a do francês G. Colomb, Lecciones de Cosas en 650 grabados, "publicada em francês pela primeira vez em 1895 e cuja adaptação hispano-americana foi realizada em 1904 pelo Editorial Gustavo Gili, de Barcelona, versão da qual se conhecem mais de 30 edições até 1966". (MARTÍNEZ MOCTEZUMA, 2010, p. 192.) ${ }^{7}$

Fartamente ilustrado (com “650 grabados”), o livro adota um procedimento explicado pelo autor no "Prólogo":

Em vez de um texto extenso e quase sempre difuso, ao qual o aluno costuma prestar pouca atenção, e no qual, por atender a pormenores, se perde geralmente de vista o objeto principal, temos adotado o sistema gráfico, no qual a gravura, que é o essencial, é acompanhada de uma explicação muito breve, mas clara (COLOMB, 1932, p. 4, grifo do autor).

Cada lição ("Pedras"; "Metais"; "A água e o ar"; "Matérias alimentícias"; "Iluminação e calefação"; "Os vestidos"; "Vegetais"; "Os inimigos e os aliados do homem"; "Matérias industriais"; "O homem"; e "Conhecimentos astronômicos") é sempre introduzida por "Noções gerais", contendo uma breve definição do tema e a explicação sobre o ramo de ciência que o estuda. Segue-se a lição propriamente dita e, depois, um "Resumo". No final do livro, há a seção "Temas", que são exemplos de atividades que o professor pode realizar com os alunos, e "Léxico", contendo, em ordem alfabética, vocábulos empregados nas lições. Estas consistem de pequenas figuras numeradas, acompanhadas de pequenos textos. Cada página é composta por um conjunto de figuras e suas respectivas explicações, além de um pequeno resumo (denominado "Texto") sobre os assuntos ali tratados.

\footnotetext{
${ }^{6}$ Utilizou-se a "21a. edição notavelmente melhorada" desde livro, com "150 gravuras". O autor, Joaquím Pla Cargol (1882-1978) é apresentado como "Professor. Ex-aluno da Faculdade dei Ciências da Universidad Central".

${ }^{7}$ Segundo Moctezuma (2010, p. 190), Colomb formou-se na "Escola Normal Superior e foi nomeado subdiretor do Laboratório de Botânica da Faculdade de Ciências da Universidade de Paris". O blog Fontesdart afirma que Georges Colomb (1856-1945), além de compor Leçons de Choses, foi um pioneiro da história em quadrinhos francesa, atendendo pelo pseudônimo de Christophe. O tradutor da obra de Colomb, Luis G. León, "fundou o Observatório Meteorológico da Escola Normal para Professoras e na Escola Nacional Preparatória, onde foi catedrático de química e física. Desempenhando essas atividades, interessou-se por temas tão particulares como a astronomia e a fotografia" (p. 191).
} 
Não há, efetivamente, nenhum suporte narrativo para as lições. Por exemplo, o texto da primeira lição ("Pedras"), cujo primeiro subtema é "Rochas principais - modo de reconhecê-las", inicia-se abruptamente, após uma figura mostrando uma jarra vertendo líquido sobre uma pedra: "Calcário - 1. Se se verte um ácido, v. g.,: vinagre, sobre uma pedra calcária (giz, mármore etc.), produz-se ebulição, efervescência” (COLOMB, 1932, p. 7). Na página seguinte, o subtema é sobre "Pedreiras e minas", e novamente o texto entra diretamente no assunto: "Quando a pedra está à flor da terra, a pedreira chama-se aberta. Dispõe-se em degraus pra que possam trabalhar nela muitos operários". (COLOMB, 1932, p. 8, grifos do autor.). Seguem-se os subtemas "Pedreiras e minas (continuação)" "Perigos das pedreiras e das minas"; "Rochas calcáreas - pedra de construção"; "Rochas calcáreas (continuação) - cré"; "Rochas calcáreas (continuação) - a cal e a argamassa"; "Rochas calcáreas (continuação) - a marga"; "Rochas calcáreas (continuação) - pedra litográfica; alabastro"; "Argila - cerâmica"; "Argila (continuação) - ladrilhos, telhas, lousa"; Sílica arenito, cristal de rocha, sílex"; "Pedras silícicas: pedra molar"; "Pedra de gesso: gesso"; "Como se faz uma estátua de mármore"; "Fabricação do vidro"; "Como se faz um vidro"; "Outras rochas". A seguir, vem a lição sobre "Metais", com suas subdivisões, e assim por diante.

Figura 1. Primeira lição, "Rochas principais", do livro de Colomb

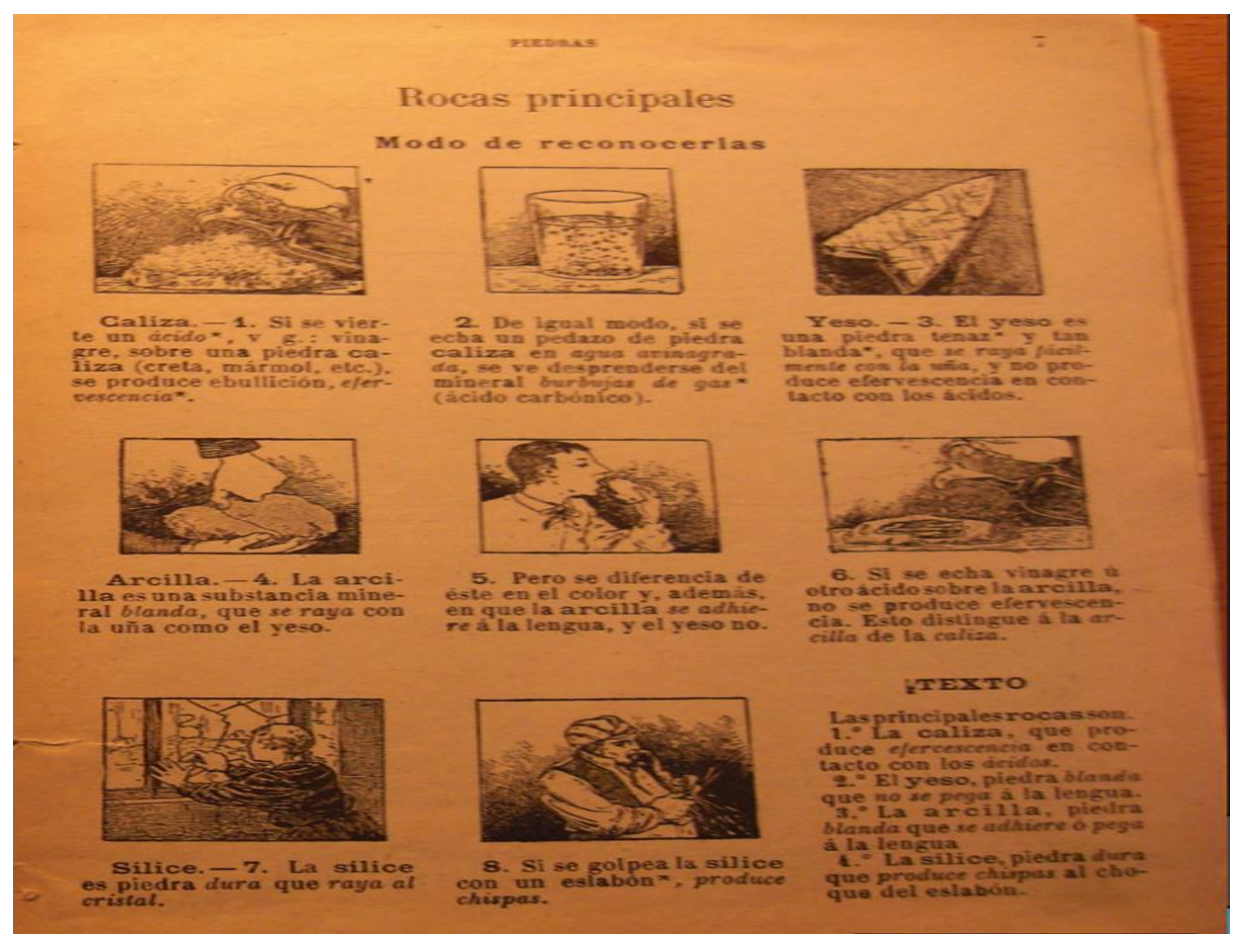

Fonte: COLOMB, G. Lecciones de Cosas en 650 grabados. Barcelona: Gustavo Gili, s.d., p. 7. 
No Brasil, Elementos de Lições de Cousas, de Córa de Alvarenga (1925), ${ }^{8}$ livro "approvado", conforme sua página de rosto, "pelo governo de Estado de Rio de Janeiro, organizado de accordo com o programma official dos grupos escolares do Estado do Rio de Janeiro", chega a parecer um dicionário, com textos dispostos como verbetes. Por exemplo, uma lição sobre "Flôr":

Flôr é um conjunto de folhas modificadas. Essas folhas são sustentadas por uma porção do caule, que toma o nome de pedunculo, e a porção dilatada onde elas se inserem chama-se receptaculo. Uma flôr completa compões-se de 4 partes: calice, corolla, androceu e gyneceu, e cada uma dessas partes chama-se verticillo. [...] $\mathrm{O}$ calice classifica-se em gamosépalo, quando os sépalos são ligados entre si, como no linho dialysepalo, quando os sépalos são separados, como na ervilha regular ou actinomorpho, quando os sépalos são iguaes e se inserem symetricamente irregular ou zigomorpho, quando os sépalos são desiguaes e se inserem sem symetria. (ALVARENGA, 1925 p. 55, grifos da autora).

No caso de La Gimnástica del Espíritu: Método maternal (1925), do francês PierreAugustin Pellissier (1819-1894), ${ }^{9}$ editado na Espanha, há uma gradação na apresentação das coisas, segundo a faixa etária a que cada parte do livro se destina. O próprio autor explica em texto introdutório endereçado "Aos Pais e aos Professores":

Observar, analisar, explicar os objetos e os seres, tal é o fundo desta Ginástica, que compreende três séries de exercícios.

PRIMEIRA PARTE - A criança de cinco a sete anos analisa os objetos e os seres, e aprende a contemplar, a decompor, a recompor e a descrever.

SEGUNDA PARTE - A criança de sete a dez anos se exercita em julgar e raciocinar, define os objetos, assenta os princípios e tira as consequências.

TERCEIRA PARTE - Nesses exercícios, o aluno de dez a treze anos reflexiona sobre si mesmo e seus primeiros deveres; e da observação da natureza física e da natureza moral, faço com que se remonte aos princípios essenciais da religião, a fim de que conheça e ame a Deus, criador e providência do mundo (PELLISIER, s.d. p. 3-4).

Como se pode ver, a religiosidade aparece na "Terceira Parte". O livro ainda conta, antes das lições propriamente ditas, com "Conselhos práticos" (p. 5), em que se apresentam rudimentos de metodologia de ensino. Em seguida, apresentam-se "Advertências aplicáveis a todos os exercícios" (p. 9), em que se retomam, na prática, os "Conselhos" anteriores, e, finalmente, "Aos discípulos", "a esperança da sociedade", a quem se buscará "ensiná-los a pensar com retidão" (p. 10). A primeira lição "A sala de aula" inicia-se com desenhos estilizados de objetos ali encontrados, com legendas, mas sem nenhuma explicação: "O livro"; "O lápis"; "O canivete"; "A régua"; "A carteira"; "O banco"; "O caderno"; "A lousa"; "O giz", "O tinteiro"; "A pena” (p. 11).

\footnotetext{
${ }^{8}$ Sobre a autora, encontraram-se apenas, no blog Autores Campistas as informações de que ela é natural da cidade de Campos (Rio de Janeiro), onde foi diretora do Grupo Escolar 15 de Novembro e que também escreveu Aritmética Elementar (1919). Não há dados sobre nascimento e morte. (Ver: http://autorescampistas. blogspot.com.br 2012/12/cora-de-alvarenga.html. Acesso em: 1 jul. 2017).

${ }^{9}$ Segundo Melcón Beltrán (2000), "Pellissier foi um homem de letras e, como professor de filosofia, tratou de revitalizar as correntes espiritualistas, prevalecendo nele as considerações didáticas sobre as científicas" (p. 155156). A autora também informa que a "primeira impressão francesa data de 1873 e que em 1905 superava 60 edições" (p. 155). A primeira edição espanhola é de 1889 e foram publicadas 12 edições até 1925 (p. 155).
} 
Figura 2. Primeira lição do livro de Pelissier

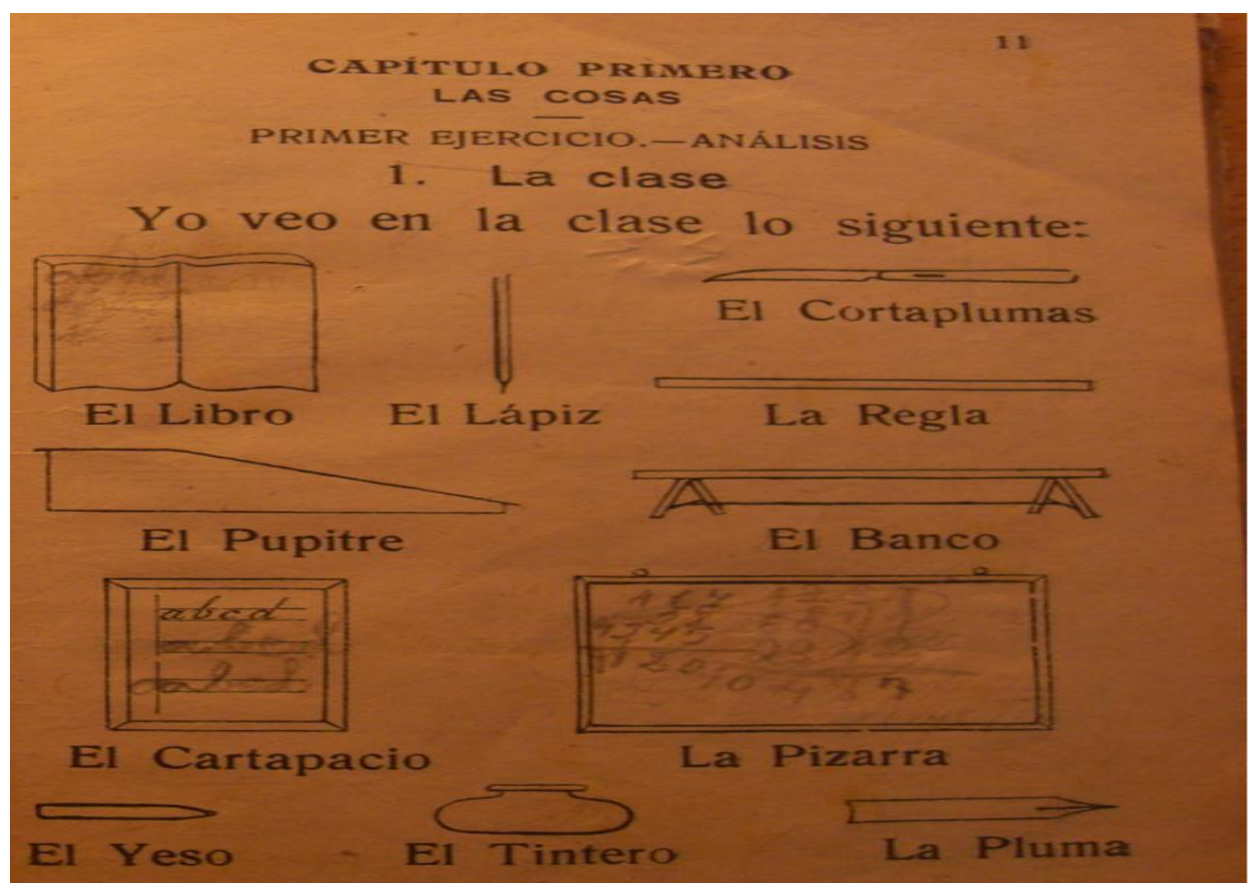

Fonte: Pellissier, A. La Gimnástica del Espíritu: Método maternal. 12ª . ed. Valencia: Librería de Pacual M. Villalba, 1925, p. 4.

Nos níveis mais avançados, a religiosidade vai se insinuando aos poucos, como já foi prescrito na introdução "Aos pais e aos professores". Por exemplo, a lição 57, "O Homem":

O olho serve para ver a cor e a figura dos objetos e dos seres.

O ouvido serve para ouvir os sons, entre outros a linguagem do homem e o canto das aves.

A mão serve para apreciar o calor o frio, a solidez e o peso dos objetos e para escrever e trabalhar.

A boca serve para comer e falar.

O pedreiro constrói toda a parte de obra, os muros e demais paredes dos edifícios.

O professor ensina as crianças a ler, escrever e contar.

O carpinteiro constrói as portas das casas e muitos tipos de móveis.

O sacerdote nos ensina a elevar o nosso coração a Deus e também roga por nós.

(PELLISIER, s.d., p. 108-109).

Essa presença do religioso ocorre em meio à explicação sobre a serventia das coisas, como se vê também na lição 59, "A Igreja e a escola": 
O livro serve para ler e aprender.

A carteira serve para guardar nela o papel, a pena, a lapiseira, a régua e os livros do aluno.

Do púlpito anuncia o sacerdote a palavra de Deus.

A cruz serve para recordar o divino sacrifício de N. S. Jesus Cristo.

$\mathrm{O}$ atril serve para pôr os livros e papéis de canto.

O altar serve para oferecer o santo sacrifício da Missa.

Os quadros servem para perpetuar algum fato memorável.

A lapiseira serve para escrever e desenhar.

A tinta serve para escrever de modo mais visível e duradouro do que com o lápis

(PELLISIER, s.d., pp. 110-111).

Essa moral, essencialmente utilitarista, está presente também na obra de Colomb (1932), como se vê na lição VIII, "Os inimigos e os aliados do homem". Como já se mostrou alhures (MUNAKATA, 2012), os seres que constituem as "coisas" sobre as quais se ministram lições são classificados em úteis e nocivos, estando descartados aqueles que não são nem uma coisa nem outra. No caso do livro de Colomb, as "Noções gerais", que antecedem a lição VIII propriamente dita, esclarece:

O homem não está só na natureza, mas em sua companhia vivem infinidade de seres. Ele é o rei da criação e como tal tem sujeitado a seu domínio todos os seres do globo terrestre, por meio da força, da astúcia ou da ciência. E ainda que seja verdade que todos lhe servem direta ou indiretamente, por condições especiais que possuem, alguns revestem o caráter de inimigos ou aliados, porque diretamente lhe acarretam alguns danos ou vantagens. (COLOMB, 1932, p. 113).

O caráter útil ou nocivo dos seres tem sempre como referência o Homem, o "rei da criação" e, por isso, dotado de poder de sujeição. Tal poder, no entanto, deve ser exercido de modo responsável:

Não se deve causar a morte de nenhum animal sem antes averiguar se é prejudicial ou útil, pois ainda os que consideramos como nocivos podem, em certas circunstâncias, prestar-nos bons serviços. (...) Por isso, além de ser moralmente mau destruir sem consideração os animais, muitas vezes é idiotice e contraproducente (COLOMB, 1932, p. 114).

O que ressalta nesses exemplos é a constituição de uma moralidade, cujo eixo central é a utilidade. Mesmo quando estão presentes aspectos da moral cristã o que é valorizado é a utilidade: no caso de Pelissier (1925), visto acima, "o sacerdote nos ensina (...) e roga por nós", mas "ensinar" e "rogar", na série apresentada, ocupam o mesmo lugar de "servir para". Da mesma forma que livro, carteira, tinta etc., as coisas religiosas, cruz, púlpito ou sacerdote, também devem servir.

Os livros de lições de coisas, ao abandonarem a retórica da narrativa, parecem ter reduzido ao mínimo o que pode ser dito sobre as coisas: o que são e para que servem. A coisa é, mas também serve. Ou melhor: é porque serve. Para Kahn (2002), as lições de coisas, no final das contas, preparariam o terreno para o ensino das ciências na escola. Mas a exigência de serventia perduraria por muito tempo, como testemunhou nos anos 1950-60 o escrevinhador destas linhas.

\section{REFERÊNCIAS}


ADAM, Jean-Michel. Narração. In CHARAUDEAU, Patrick; MAINGUENEAU, Dominique (org.). Dicionário de Análise do Discurso. São Paulo: Contexto, 2004.

ALCANFOR, Lucilene Rezende. Produção e circulação das obras didáticas de Monteiro Lobato. Dissertação de Mestrado. São Paulo: PUC-SP, 2010.

BIANCO, Judite Elide Romero. As Lições de coisas no projeto republicana paulista (18901920). Dissertação (Mestrado) - Faculdade de História, Direito e Serviço Social, Universidade Estadual Paulista (Campus Franca), 1999.

CARUSO, Marcelo. La biopolítica en las aulas. Prácticas de conducción em las escuelas elementares del reino de Baviera, Alemanha (1869-1919). Buenos Aires: Prometeo, 2005.

HÉBRARD, Jean. Três figuras de jovens leitores: alfabetização e escolarização do ponto de vista da história cultural. In: ABREU, Márcia (org.). Leitura, história, e história da leitura. Campinas: Mercado de Letras; São Paulo: Fapesp, 2002, p. 33-77.

KAHN, Pierre. La Leçon de Choses. Naissance de l'enseignement des sciences à l'école primaire. Villeneuve d'Áscq Cédex: Presses Univeristaires du Septentrion, 2002.

MARTÍNEZ MOCTEZUMA, Lucía. Paseando con la Ciencia: los libros de "Lecciones de Cosas" (1889-1921). In MARTÍNEZ MOCTEZUMA, Lucía; GALVÁN LAFARGA, Luz Elena (coord.). Las Disciplinas Escolares y Sus Libros. México: Centro de Investigaciones y Estudios Superiores en Antropología Social / Universidad Autónoma del Estado de Morelos / Juan Pablo Editor, 2010, p. 185-213.

MEDINA, Camila Beltrão. Lições de coisas e sua transposição para livros de leitura brasileiros (1907-1945): A história da educação pela clivagem do impresso. Tese (Doutorado) - Faculdade de Educação, Universidade de São Paulo, 2012.

MELCÓN BELTRÁN, Julia. Currículo escolar y lecciones de cosas. In TIANA FERRER, Alejandro (org.). El Libro Escolar, reflejo de intenciones políticas e influencias pedagógicas. Madrid: Universidade Nacional de Educación a Distancia, 2000, p. 135-160.

MUNAKATA, Kazumi. Que coisa é coisa das Lições de Coisas? In Oliveira, Marcus Aurélio Taborda de (org.). Sentidos e sensibilidades: sua educação na história. Curitiba: Editora UFPR, 2012, pp. 21-27. 
SCHELBAUER, Analete Regina. A Constituição do Método de Ensino Intuitivo na Província de São Paulo (1870-1889). Tese (Doutorado) - Faculdade de Educação, Universidade de São Paulo, 2003.

SOUZA, Rosa Fátima de. Templos de civilização: um estudo sobre a implantação dos grupos escolares no Estado de São Paulo (1890-1910). São Paulo: UNESP, 1999.

VALDEMARIN, Vera Teresa. Estudando as lições de coisas: análise dos fundamentos filosóficos do Método de Ensino Intuitivo. Campinas: Autores Associados, 2004.

\section{Fontes}

ALVARENGA, Córa de. Elementos de Lições de Cousas. 9. ed. São Paulo: Typografia Siqueira, 1925.

CALKINS, N. A. Primeiras Lições de Coisas. Manual de Ensino Elementar para uso dos pais e professores. Vertido da 40a edição e adaptado as condições do nosso idioma e paizes que o falam pelo Conselheiro Ruy Barbosa. Rio de Janeiro: Imprensa Nacional: 1886.

COLOMB, G. Lecciones de Cosas en 650 grabados. Adaptación hispano-americana por el profesor Luis G. León. Cuarta edición corregida y aumentada con licencia. Barcelona: Gustavo Gili, s.d.

DR. SAFFRAY. Lições de Cousas. Traduzidas da ultima edição francesa para uso das classes de instrução primaria por M. C. Mesquita Portugal. Autalizada. Porto: Chardron / Rio de Janeiro: Livraria Clássica, s.d.

JOST, C. [sic, na realidade Guillaume]; Humbert, V. Lições de Cousas. Leituras praticas. Rio de Janeiro / Paris: Garnier, s.d.

PAPE-CARPENTIER, Marie. Enseignement par les yeux. Zoologie des salles d'asile et des écoles élémentaires. 9. ed., 1911.

PAPE-CARPENTIER, Marie. Histoires et Leçons de Choses. Pour les enfants. 16. ed. Paris: Hachette. 1904.

PELLISIER, A. La Gymnástica del Espíritu (Método maternal). Primera parete. Observación de las cosas y de las seres. Modelos y asuntos de ejercicios orales y escritos para los niños de ambos sexos. 12. ed. Valencia: Librería de Pascual M. Villalba, s.d. 
PLA CARGOL, Joaquín. Otras Lecciones de Cosas (Lecturas cienfíficas). 21. edición notablemente mejoada. Gerona / Madrid: Dalmáu Carles, Pla, S.A., s.d.

RICKS, George. Object Lessons and how to give them. Boston. D. C. Heath \& Co. Publishers, 1895.

SHELDON. E. A. A Manual of Elementary Instruction for the Use of public and privite schools and normal classes. New York: Scriber, Armstrong \& Co., 1872.

STAURENGHI CONSIGLIO, Virginia. Lezioni di cose secondo l'ordine naturale intuitivo per le scuole elementari. Torino: Stamperia Reale Della Ditta G. B. Paravia e Comp., 1880.

Recebido: 20/03/2017

Aprovado: 10/04/2017 